\title{
Reliability Assessment of Repairable Systems Using Simple Regression Models
}

\author{
Miguel Ángel Navas Álvarez \\ Department of Electrical, Electronic and Control Engineering, \\ Spanish National Distance Education University, Madrid, CP28040, Spain. \\ Corresponding author: mnavas65@alumno.uned.es \\ José Carpio Ibáñez \\ Department of Electrical, Electronic and Control Engineering, \\ Spanish National Distance Education University, Madrid, CP28040, Spain. \\ E-mail: jcarpio@ieec.uned.es \\ Carlos Sancho de Mingo \\ Department of Electrical, Electronic and Control Engineering, \\ Spanish National Distance Education University, Madrid, CP28040, Spain. \\ E-mail: csancho@ieec.uned.es
}

(Received February 26, 2020; Accepted April 29, 2020)

\begin{abstract}
The statistical nature of failures in repairable systems does not have a behaviour similar to non-repairable systems. The statistical models developed for the study of the reliability of repairable systems mostly based on the application of stochastic processes. However, there is a group of prediction models for reliability based on time series analysis. Below are the results and conclusions of the application of simple regression models in the escalators Avante model (TNE), in order to assess their potential use by maintenance organizations.
\end{abstract}

Keywords- Repairable system, Reliability models, Simple regression, Escalators.

\section{Introduction}

Much of the developed statistical models for the study of the reliability of repairable systems based on the application of stochastic processes in which a failure of an element is a random variable, and once repaired the next failure is another random variable, which may or may not have equal probability density function. The most commonly used stochastic models are Markov chains, Homogeneous Poisson Processes (HPP), Non-Homogeneous Poisson Processes (NHPP) and Renewal Processes (RP). Most of the Markov chain methods based on two-state models (Kumamoto et al., 1980; Simpson and Kelly, 2002; Xiao and Li, 2008; Zheng et al., 2006), and to a lesser extent, models with multi-state Markov chains have developed.

The HPP model can only applied if it demonstrated that the Time Between Failure (TBF) data of the repairable system are independent, stationary and with exponential distribution (Tan et al., 2008; Wu et al., 2011). The NHPP model applies if the repairable system TBF data shown to be independent and non-stationary, being the Power Law Process (PLP) the most extended (Crow, 1975). Multiple NHPP models have published with alternative functions to PLP (Attardi and Pulcini, 2005; Bettini et al., 2007). 
International Journal of Mathematical, Engineering and Management Sciences

Vol. 6, No. 1, 180-192, 2021

https://doi.org/10.33889/IJMEMS.2021.6.1.011

RP models apply if TBF data from the serviceable system is shown to be independent, stationary, and with any distribution. The mathematical solution for this integral equation with convolution is complex and must particularized to each distribution presented by the TBF (Baxter et al., 1982; Andronov, 2014; Maghsoodloo and Helvaci, 2014).

There are also multiple models based on imperfect stochastic processes. Initiated with the Branching Poisson Process (BPP) (Lewis, 1964) and with the Modulated Renewal Process (MRP) (Cox, 1972). Other "imperfect repair" models are:

- Brown and Proschan (BP) (Brown and Proschan, 1983).

- Brown, Borges and Savits (BBS) (Block et al., 1985).

- Trend Renewal Processes (TRP) (Lindqvist et al., (2003).

- Generalized Renewal Processes (GRP) (Kijima, 1989).

- Proportional Intensity (PI) (Jiang et al., 2005).

- Fragility models for correlated data (Peña and Hollander, 2004).

The number of stochastic models developed far exceeds one hundred (Ascher and Feingold, 1984; Guo et al., 2000; Peña, 2006; Pham and Wang, 1996; Rigdon and Basu, 2000; Rausand and Hoyland, 2004).

The difficulty lies in choosing the most appropriate model for the data of the repairable systems under study, and although the scientific community has reached some meeting points regarding the applicability of the HPP, NHPP and RP models. To date, there is no consensus in relation to which imperfect models (or others) are the most appropriate to try to model those repairable systems that do not can apply to the HPP, NHPP or RP models.

The intensive development over decades of statistical models for the reliability of repairable systems denotes the great complexity of the treatment and modelling of the real data obtained in the systems in operation. Most of these models based on stochastic processes, but not all. There are statistical models of reliability that not based on stochastic processes:

- Models of differential equations, Lloyd-Lipow (design phase), Aroef, IBM, etc. Most developed in the 60s.

- Cumulative damage shock models, for example the Kijima model (Kijima and Nakagawa, 1991). They are suitable models for mechanical components.

- Monte Carlo models, (Kaminskiy and Krivtsov, 1998).

- No parametric models, (Block et al., 2013; Gámiz et al., 2011; Nelson, 2003).

- Prediction models based on neural networks, (Liang, 2008; Tong and Liang, 2005).

- Models with multivariate dependence, (Ma and Krings, 2008; Yang et al., 2013).

- Prediction models based on time series analysis, (Liang, 2011). This paper classified within this group of models.

Reliability prediction models through time series analysis start from a data-oriented approach, which does not require a priori model specification. This time series technique has the flexibility to fit an appropriate empirical model, which is an adaptation of the data structure itself. 
International Journal of Mathematical, Engineering and Management Sciences

Vol. 6, No. 1, 180-192, 2021

https://doi.org/10.33889/IJMEMS.2021.6.1.011

Therefore, the stochastic nature of the time series can be model with greater precision, although it is necessary to use self-correlation, partial correlation and spectral analysis tools to examine the underlying properties of the data, such as the existence of no seasonality, trend, etc.

Stand out as reliability prediction models based on time series analysis:

- Exponential Smoothing model (ES).

- Moving Average model (MA).

- Autoregressive Box-Jenkins ARIMA model (Autoregressive Integrated Moving Average Process)

- Box-Jenkins SARIMA model (Seasonal Autoregressive Integrated Moving Average Process).

- Regression models. This paper classified within this group of models.

Reliability regression models are oriented to construct a statistical model that describes the impact of one or more quantitative factors on a dependent variable. It is about finding the model that best fits the data, without needing to understand and explain the origin of the behaviour of the TBF. The regression methods commonly applied to reliability models are: simple, multiple, logistics, negative binomial, nonlinear, polynomial, Poisson and Cox proportional hazards.

In this paper, 27 simple regression models are tested and evaluated on the failure data of 40 escalators to model their reliability. The main advantage of this type of tests with respect to other models, is that the tests are simpler, require less technical resources and data processing times, quickly obtaining the presentation of results.

\section{The System Tested}

The escalator defined as a motorized ladder, inclined and in continuous movement, used to raise or lower people on which the transport surface, for example stairs that remain horizontal. The escalators made up of repairable components that, if they fail, replaced by other useful spare parts, the electromechanical components being predominant.

The escalators object of this test are of the TNE model and installed in a subway system in 2005, their large building blocks corresponding to those represented in Figure 1.

Regarding the type and treatment of the data, there is continuous and complete data for a finite population without sampling. They are quantitative data, uncensored and truncated by time, validated at source and without screening. No failure record is deleted, even if the distribution appears initially abnormal or outside the expected system values.

The 40 escalators of the TNE series under study have the same technical and constructive design, as well as the same operational context. The failures records correspond to the period of 2005-2014. The accumulated operating hours for each escalator exceed 67,000 hours. 
International Journal of Mathematical, Engineering and Management Sciences

Vol. 6, No. 1, 180-192, 2021

https://doi.org/10.33889/IJMEMS.2021.6.1.011

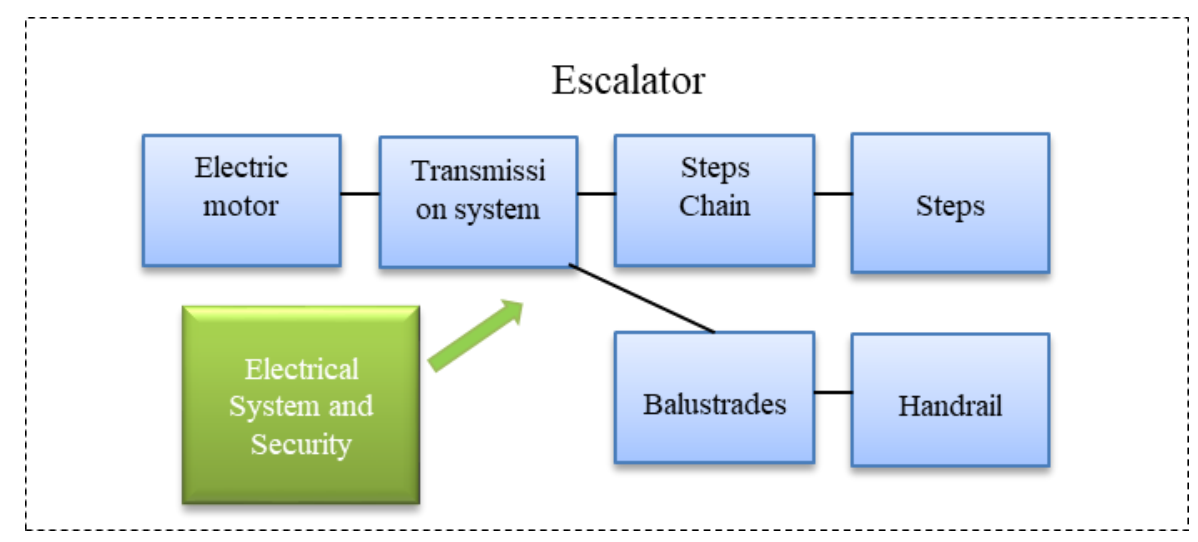

Figure 1. Building blocks of a TNE escalator.

\section{Selected Models and Formulation}

The models chosen for reliability estimation of the 40 escalators are simple regression (least squares method). It has chosen to test these models, knowing the high volume of data to be processed and taking into account the available resources, in order to assess their ability to adjust to the data and level of acceptance.

27 simple regression models have been tested, with or without prior transformation of values of the $X$ axis in hours $(h)$, and of the $Y$ axis the expected cumulative number of failures $E[N(t)]$, with the coefficient $\beta_{0}=0$ in all models, since $E[N(0)]=0$.

For each escalator, the regression model that best adapted to the data was selected, that is, the one with a higher of $R^{2}$ determination coefficient adjusted in a range from zero to $100 \%$. The goodnessof-fit test integrated within the ANOVA (analysis of variance) model by decomposing the variability of the dependent variable $Y$ into a sum of squares model of the error or residues.

Of particular interest in this analysis is the test $F$ and its associated $P$-value to test the statistical significance of the adjusted model. A small $P$-value (less than 0.05 at a significance level of 5\%) indicates that a statistical relationship of the specified form exists between $Y$ and $X$.

The formulation of simple regression models to better acceptance testing goodness of fit tests on 27 models of the 40 escalators attached.

Linear,

$E[N(t)]=\beta_{1} h$

Square root of $x$,

$E[N(t)]=\beta_{1} \sqrt{h}$ 
International Journal of Mathematical, Engineering and Management Sciences

Vol. 6, No. 1, 180-192, 2021

https://doi.org/10.33889/IJMEMS.2021.6.1.011

Square of $x$,

$E[N(t)]=\beta_{1} h^{2}$

Square of $y$, square of $x$,

$E[N(t)]=\sqrt{\beta_{1} h^{2}}$

\section{Tests and Numerical Examples}

The total number of failure records of the 40 escalators in the study period is 8,837 . There is an important and detailed database, which ensures that the results obtained in statistical tests have an adequate degree of integrity, see summary in Table 1.

Table 1. Summary of failures data in TNE escalators.

\begin{tabular}{|c|c|c|}
\hline Escalator & Total Hours & Total Failures \\
\hline 1 & 72,620 & 202 \\
\hline 2 & 72,620 & 166 \\
\hline 3 & 72,000 & 151 \\
\hline 4 & 72,000 & 174 \\
\hline 5 & 71,640 & 389 \\
\hline 6 & 71,640 & 144 \\
\hline 7 & 71,860 & 214 \\
\hline 8 & 71,440 & 273 \\
\hline 9 & 71,440 & 301 \\
\hline 10 & 71,300 & 169 \\
\hline 11 & 71,100 & 193 \\
\hline 12 & 70,880 & 283 \\
\hline 13 & 70,800 & 335 \\
\hline 14 & 70,800 & 255 \\
\hline 15 & 70,800 & 326 \\
\hline 16 & 70,500 & 275 \\
\hline 17 & 70,460 & 171 \\
\hline 18 & 70,480 & 128 \\
\hline 19 & 70,380 & 152 \\
\hline 20 & 70,320 & 201 \\
\hline
\end{tabular}

\begin{tabular}{|c|c|c|}
\hline Escalator & Total Hours & Total Failures \\
\hline 21 & 70,120 & 186 \\
\hline 22 & 69,920 & 259 \\
\hline 23 & 69,760 & 256 \\
\hline 24 & 69,640 & 306 \\
\hline 25 & 69,500 & 292 \\
\hline 26 & 69,480 & 347 \\
\hline 27 & 69,360 & 124 \\
\hline 28 & 69,340 & 289 \\
\hline 29 & 69,280 & 293 \\
\hline 30 & 69,200 & 109 \\
\hline 31 & 69,080 & 197 \\
\hline 32 & 68,980 & 131 \\
\hline 33 & 68,360 & 281 \\
\hline 34 & 68,120 & 280 \\
\hline 35 & 68,080 & 286 \\
\hline 36 & 67,100 & 126 \\
\hline 37 & 67,100 & 172 \\
\hline 38 & 67,100 & 63 \\
\hline 39 & 67,100 & 183 \\
\hline 40 & 67,100 & 155 \\
\hline
\end{tabular}

For each escalator, 27 simple regression models have tested, presenting the results in Table 2 of the model that has obtained a better fit to the failure data. 
International Journal of Mathematical, Engineering and Management Sciences

Vol. 6, No. 1, 180-192, 2021

https://doi.org/10.33889/IJMEMS.2021.6.1.011

Table 2. Estimated simple regression models of $E[N(t)]$ on escalators model TNE.

\begin{tabular}{|c|c|c|c|}
\hline Escalator & Best simple regression & Model $\beta$ parameter & Trend of the regression model \\
\hline 1 & Linear & $2.65 \mathrm{E}^{-03}$ & Without trend \\
\hline 2 & Linear & $2.20 \mathrm{E}^{-03}$ & Without trend \\
\hline 3 & Linear & $2.30 \mathrm{E}^{-03}$ & Without trend \\
\hline 4 & Square root of $x$ & $6.25 \mathrm{E}^{-01}$ & Decreasing \\
\hline 5 & Linear & $4.81 \mathrm{E}^{-03}$ & Without trend \\
\hline 6 & Linear & $2.21 \mathrm{E}^{-03}$ & Without trend \\
\hline 7 & Linear & $2.86 \mathrm{E}^{-03}$ & Without trend \\
\hline 8 & Linear & $3.72 \mathrm{E}^{-03}$ & Without trend \\
\hline 9 & Linear & $4.47 \mathrm{E}^{-03}$ & Without trend \\
\hline 10 & Linear & $2.33 \mathrm{E}^{-03}$ & Without trend \\
\hline 11 & Linear & $2.62 \mathrm{E}^{-03}$ & Without trend \\
\hline 12 & Square of $y$, square of $x$ & $1.54 \mathrm{E}^{-05}$ & Without trend \\
\hline 13 & Linear & $4.54 \mathrm{E}^{-03}$ & Without trend \\
\hline 14 & Linear & $3.36 \mathrm{E}^{-03}$ & Without trend \\
\hline 15 & Square of $x$ & $7.95 \mathrm{E}^{-08}$ & Growing \\
\hline 16 & Linear & $3.48 \mathrm{E}^{-03}$ & Without trend \\
\hline 17 & Linear & $2.50 \mathrm{E}^{-03}$ & Without trend \\
\hline 18 & Linear & $1.88 \mathrm{E}^{-03}$ & Without trend \\
\hline 19 & Linear & $2.01 \mathrm{E}^{-03}$ & Without trend \\
\hline 20 & Linear & $3.27 \mathrm{E}^{-03}$ & Without trend \\
\hline 21 & Square of $y$, square of $x$ & $6.79 \mathrm{E}^{-06}$ & Without trend \\
\hline 22 & Linear & $4.02 \mathrm{E}^{-03}$ & Without trend \\
\hline 23 & Square of $x$ & $5.10 \mathrm{E}^{-08}$ & Growing \\
\hline 24 & Linear & $4.43 \mathrm{E}^{-03}$ & Without trend \\
\hline 25 & Linear & $3.67 \mathrm{E}^{-03}$ & Without trend \\
\hline 26 & Linear & $4.59 \mathrm{E}^{-03}$ & Without trend \\
\hline 27 & Linear & $1.75 \mathrm{E}^{-03}$ & Without trend \\
\hline 28 & Linear & $4.43 \mathrm{E}^{-03}$ & Without trend \\
\hline 29 & Linear & $4.32 \mathrm{E}^{-03}$ & Without trend \\
\hline 30 & Linear & $1.22 \mathrm{E}^{-03}$ & Without trend \\
\hline 31 & Square of $y$, square of $x$ & $9.26 \mathrm{E}^{-06}$ & Without trend \\
\hline 32 & Linear & $1.87 \mathrm{E}^{-03}$ & Without trend \\
\hline 33 & Square root of $x$ & $9.83 \mathrm{E}^{-01}$ & Decreasing \\
\hline 34 & Linear & $4.41 \mathrm{E}^{-03}$ & Without trend \\
\hline 35 & Linear & $3.74 \mathrm{E}^{-03}$ & Without trend \\
\hline 36 & Linear & $1.86 \mathrm{E}^{-03}$ & Without trend \\
\hline 37 & Square of $x$ & $3.98 \mathrm{E}^{-08}$ & Growing \\
\hline 38 & Square of $x$ & $1.34 \mathrm{E}^{-08}$ & Growing \\
\hline 39 & Square of $x$ & $4.19 \mathrm{E}^{-08}$ & Growing \\
\hline 40 & Linear & $2.12 \mathrm{E}^{-03}$ & Without trend \\
\hline
\end{tabular}

In 30 escalators, the simple regression model of $E[N(t)]$ that best fits is linear and has no trend to failure (constant). There are 3 escalators with no trend of failures that have the best model as the square of $y$, square of $x$. For the 5 escalators with the growing trend in the failures, the best accepted regression simple model is the square of $x$. For the 2 escalators with the decreasing trend in failures, the best adjusted simple regression model is the square root of $x$. 
International Journal of Mathematical, Engineering and Management Sciences

Vol. 6, No. 1, 180-192, 2021

https://doi.org/10.33889/IJMEMS.2021.6.1.011

Figure 2 shows the linear simple regression model without trend to failures for the escalator number 6.

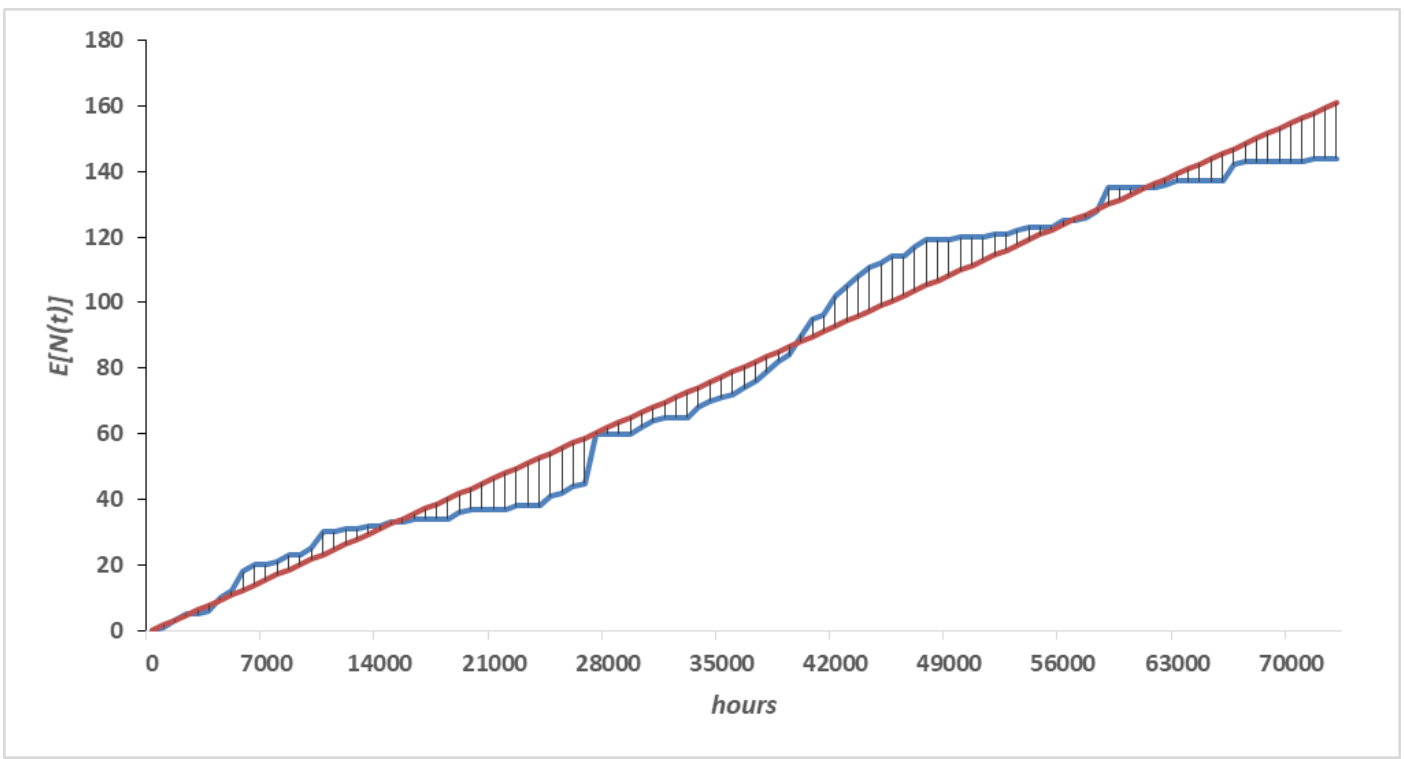

Figure 2. Linear simple regression model of the escalator number 6 .

Figure 3 shows the square double simple regression model without trend in failures for the escalator number 12 .

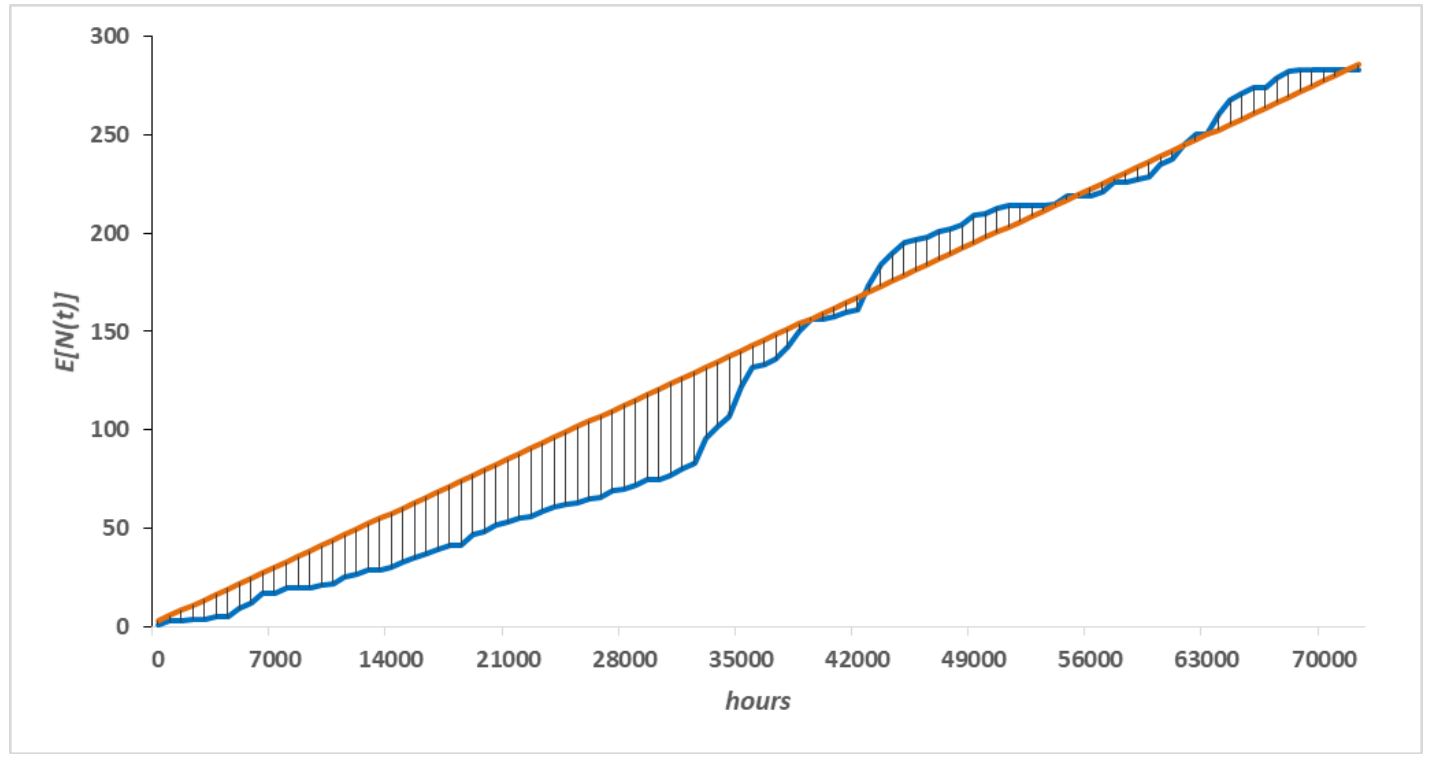

Figure 3. Square double single regression model of the escalator number 12. 
International Journal of Mathematical, Engineering and Management Sciences

Vol. 6, No. 1, 180-192, 2021

https://doi.org/10.33889/IJMEMS.2021.6.1.011

Figure 4 shows the square root of $x$ simple regression model with decreasing trend in failures for the escalator number 4.

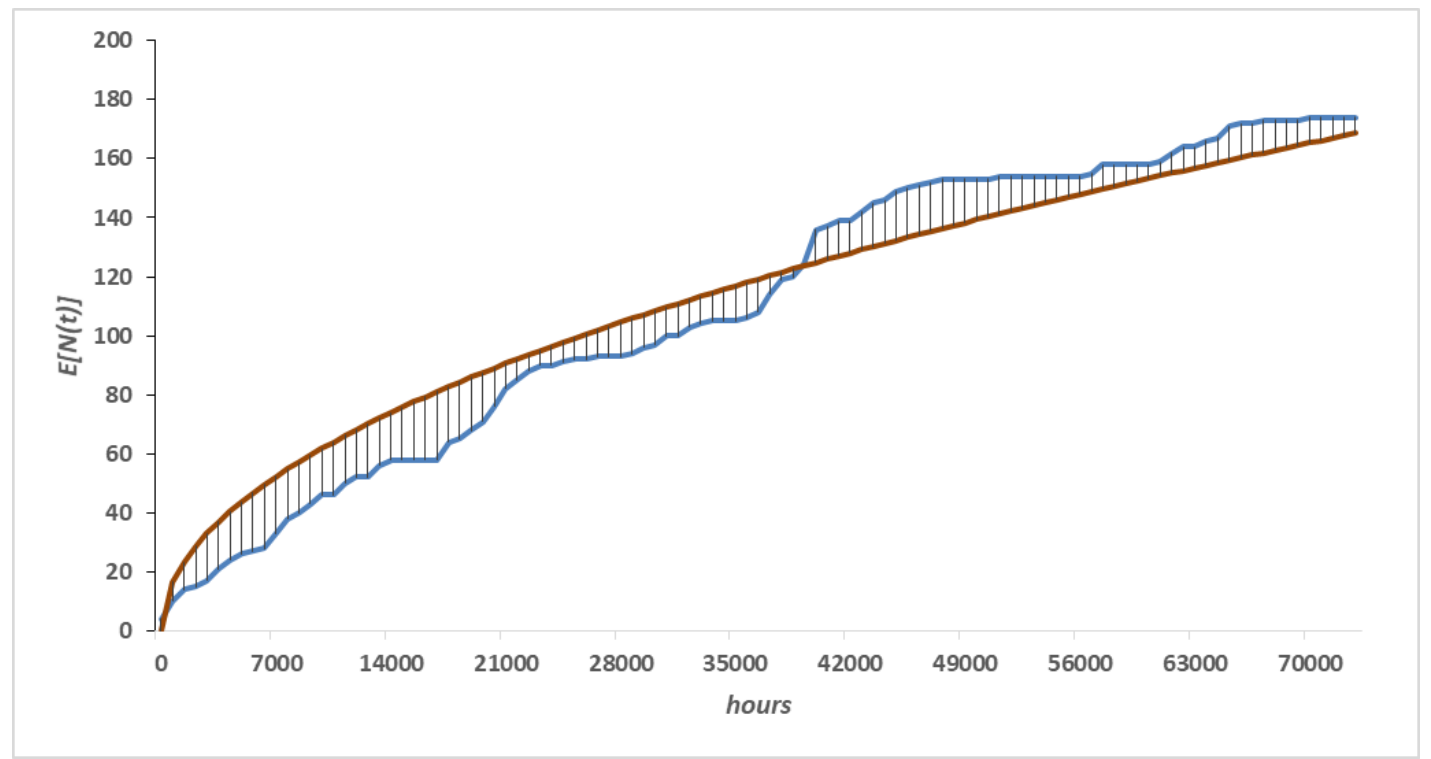

Figure 4. Square root of $x$ simple regression model of the escalator number 4 .

Figure 5 shows the square of $x$ simple regression model with growing trend in failures for the escalator number 23.

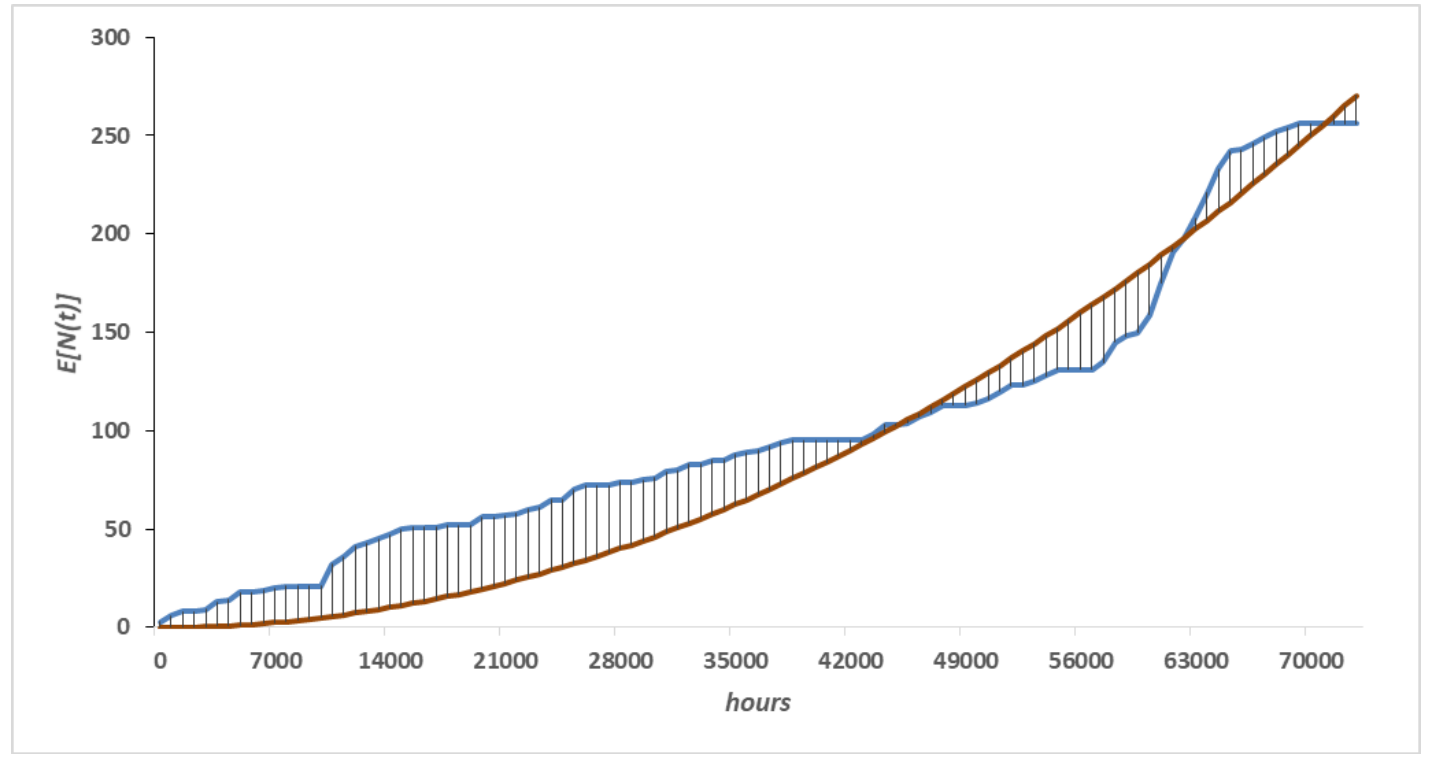

Figure 5. Square of $x$ simple regression model of the escalator number 23 . 
International Journal of Mathematical, Engineering and Management Sciences

Vol. 6, No. 1, 180-192, 2021

https://doi.org/10.33889/IJMEMS.2021.6.1.011

After more than 67,000 hours of operation of each escalator a large majority that does not have a trend to failures, but there is a significant dispersion in the value of $E[N(t)]$. This result does not seem to be the expected one in the case of escalators with the same technical and constructive design, as well as the same operational context. For example, escalator 38 accumulates 63 failures, while escalator 5 has 389 failures.

In all escalators observed that TBFs have the accumulation of several consecutive failures during short time periods, which precede and precede long time periods without accumulated failures. This widespread phenomenon in repairable systems called repetitive failures and they accumulate during operating life.

Repetitive failures have their origin in different causes of difficult diagnosis, such as the correct repair of complex repairable systems (Hatton, 1999; Karanikas, 2013). Repetitive failures have given rise to multiple models based on imperfect stochastic processes.

The differences of the $E[N(t)]$ obtained for each escalator are shown in Figure 6. In the foreground are the escalators with a lower $E[N(t)]$ at the end of the test, ordered increasingly to the escalator with a higher value of $E[N(t)]$.

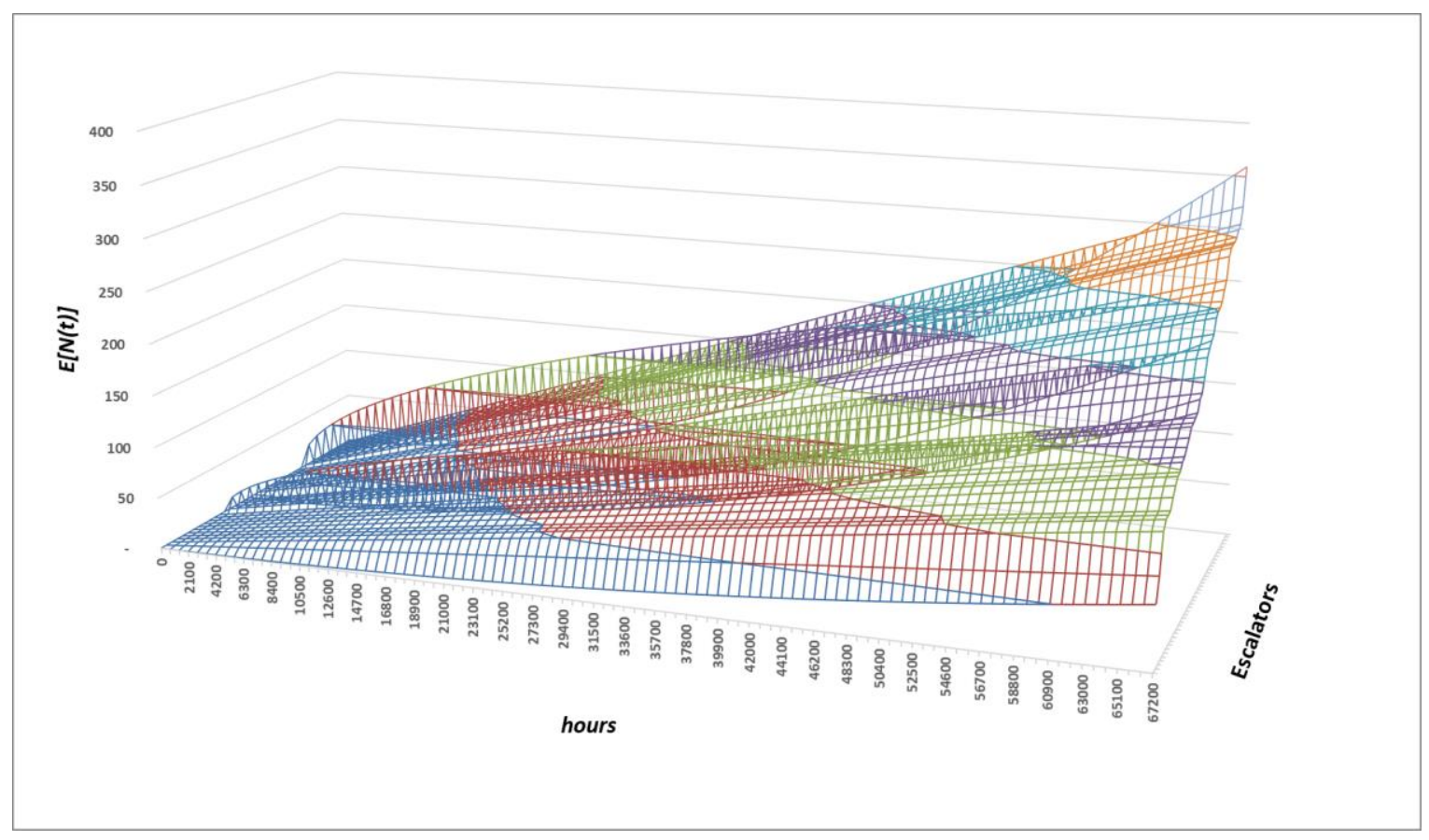

Figure 6. 3D graphic representation of the $E[N(t)]$ models of the TNE escalators.

Figure 6 visualizes the dispersion of the $E[N(t)]$ of the escalators and how the values diverge with the passage of operating hours. In most escalators, $E[N(t)]$ are presented without trend to failures. These graphs clearly show the escalators that have better and worse reliability results, as well as the trend of failures in each case. 
International Journal of Mathematical, Engineering and Management Sciences

Vol. 6, No. 1, 180-192, 2021

https://doi.org/10.33889/IJMEMS.2021.6.1.011

The main findings listed in the results of the tests carried out:

(i) For escalators with no trend in failures, the most accepted simple regression model is linear.

(ii) For escalators with an increasing trend in failures, the most accepted simple regression model is the square of $x$.

(iii) For escalators with a decreasing trend in failures, the most accepted simple regression model is the square root of $x$.

(iv) There is a significant dispersion in the value of $E[N(t)]$ among the 40 escalators, being identical, as a consequence of the accumulation of repetitive failures.

(v) The 3D graphical representation of the $E[N(t)]$ models allows us to clearly observe the different trends in the reliability of each escalator, as well as the set, in order to establish differentiated maintenance strategies for each case.

\section{Discussions and Limitation}

The tests carried out for the estimation of the reliability by means of simple regression models (least squares method) of $E[N(t)]$, have achieved a wide acceptance in the tests of goodness of fit, consuming low resources in the treatment of the data, the performance of the tests and the obtaining of results.

In the application to 40 escalators, it is observed that 33 escalators do not show a trend in $E[N(t)]$, 5 escalators have a growing trend and 3 escalators decreasing trend. The most striking result is the range of values of $E[N(t)]$ values of each escalator at the end of the test, exceeding 67,000 operating hours, which is 63 to 389 failures.

Among the limitations of this study, it is highlighted that for each escalator, more than one simple regression model has been accepted in the tests of goodness of fit, between 3 to 6 models, although the model that has been presented for each escalator a bigger fit to TBF data.

The systematic occurrence of repetitive failures observed in all escalators, which condition and cause some escalators accumulate many more failures as others, over long periods of operation.

\section{Conclusions}

Reliability models based on time series analysis are an alternative to models based on stochastic processes, when limited consumption of human and technical resources is required in the processing of data and tests, as well as obtaining results quickly.

These models, not having to adjust to an a priori model, obtain a high degree of acceptance in the goodness of fit tests, even with TBF with errant behaviours or complex explanation, as a contrast to the high levels of rejection that are usually obtained by testing models based on stochastic processes.

Reliability models based on time series analysis help limited to explain the behaviour of TBF, only to represent them with the least error the data, but they are a tool that due to its ease of compression and rapidity in obtaining results, they are very attractive to maintenance managers. 
International Journal of Mathematical, Engineering and Management Sciences

Vol. 6, No. 1, 180-192, 2021

https://doi.org/10.33889/IJMEMS.2021.6.1.011

As new lines of research, it proposed to analyze the degree of adjustment of the predictions of reliability of the models obtained, with respect to the real values of failure "a posteriori" of the test, in order to verify the practical suitability of prediction in these models.

\section{Conflict of Interest}

The authors confirm that there is no conflict of interest to declare for this publication.

\section{Acknowledgments}

Our sincere thanks to Metro de Madrid, for providing data failures escalators, without which it could have not done this assessment of reliability models.

\section{References}

Andronov, A. (2014). Resampling estimators of the renewal function. Journal of Mathematical Sciences, 196(1), 3-10.

Ascher, H., \& Feingold, H. (1984). Repairable system reliability. Marcel Dekker, New York.

Attardi, L., \& Pulcini, G. (2005). A new model for repairable systems with bounded failure intensity. IEEE Transactions on Reliability, 54(4), 572-582.

Baxter, L.A., Scheuer, E.M., McConalogue, D.J., \& Blischke, W.R. (1982). On the tabulation of the renewal function. Technometrics, 24(2), 151-156.

Bettini, G., Giansante, R., \& Tucci, M. (2007, January). Forecasting fleet warranty returns using modified reliability growth analysis. In 2007 Annual Reliability and Maintainability Symposium (pp. 350-355). IEEE. Orlando, Florida.

Block, H.W., Borges, W.S., \& Savits, T.H. (1985). Age-dependent minimal repair. Journal of Applied Probability, 22(2), 370-385.

Block, J., Ahmadi, A., Tyrberg, T., \& Kumar, U. (2013). Fleet-level reliability analysis of repairable units: a non-parametric approach using the mean cumulative function. International Journal of Pedagogy, Innovation and New Technologies, 9(3), 333-344.

Brown, M., \& Proschan, F. (1983). Imperfect repair. Journal of Applied Probability, 20(4), 851-859.

Cox, D.R. (1972). The statistical analysis of dependencies in point processes. In: Lewis, P.A. (ed) Stochastic Point Processes. pp. 55-56. New York: Wiley.

Crow, L.H. (1975). Reliability analysis for complex, repairable systems. US Army Materiel Systems Analysis Activity, Aberdeen Proving Ground, Maryland.

Gịmiz, M.L., Kulasekera, K.B., Limnios, N., \& Lindqvist, B.H. (2011). Applied nonparametric statistics in reliability. Springer Science \& Business Media, London.

Guo, R., Ascher, H., \& Love, E. (2000). Generalized models of repairable systems - a survey via stochastic processes formalism. ORiON, 16(2), 87-128.

Hatton, L. (1999). Repetitive failure, feedback and the lost art of diagnosis. Journal of Systems and Software, 47(2-3), 183-188.

Jiang, S.T., Landers, T.L., \& Rhoads, T.R. (2005). Semi-parametric proportional intensity models robustness for right-censored recurrent failure data. Reliability Engineering \& System Safety, 90(1), 91-98. 
International Journal of Mathematical, Engineering and Management Sciences

Vol. 6, No. 1, 180-192, 2021

https://doi.org/10.33889/IJMEMS.2021.6.1.011

Kaminskiy, M.P., \& Krivtsov, V.V. (1998). A Monte Carlo approach to repairable system reliability analysis. In: Mosleh, A., Bari, R.A. (eds) Probabilistic Safety Assessment and Management. Springer, New York, pp. 1063-1068.

Karanikas, N. (2013). Using reliability indicators to explore human factors issues in maintenance databases. International Journal of Quality \& Reliability Management, 30(2), 116-128.

Kijima, M. (1989). Some results for repairable systems with general repair. Journal of Applied Probability, 26(1), 89-102.

Kijima, M., \& Nakagawa, T. (1991). A cumulative damage shock model with imperfect preventive maintenance. Naval Research Logistics, 38(2), 145-156.

Kumamoto, H., Tanaka, K., Inoue, K., \& Henley, E.J. (1980). State-transition Monte Carlo for evaluating large, repairable systems. IEEE Transactions on Reliability, 29(5), 376-380.

Lewis, P.A. (1964). A branching Poisson process model for the analysis of computer failure patterns. Journal of the Royal Statistical Society: Series B (Methodological), 26(3), 398-441.

Liang, Y. (2008). Combining neural networks and genetic algorithms for predicting the reliability of repairable systems. International Journal of Quality \& Reliability Management, 25(2), 201-210.

Liang, Y. (2011). Analyzing and forecasting the reliability for repairable systems using the time series decomposition method. International Journal of Quality \& Reliability Management, 28(3), 317-327.

Lindqvist, B.H., Elvebakk, G., \& Heggland, K. (2003). The trend-renewal process for statistical analysis of repairable systems. Technometrics, $45(1), 31-44$.

Ma, Z., \& Krings, A.W. (2008, March). Multivariate survival analysis (I): shared frailty approaches to reliability and dependence modelling. In 2008 IEEE Aerospace Conference (pp. 1-21). IEEE. Big Sky, Montana.

Maghsoodloo, S., \& Helvaci, D. (2014). Renewal and renewal-intensity functions with minimal repair. Journal of Quality and Reliability Engineering, 2014, 1-10.

Nelson, W.B. (2003). Recurrent events data analysis for product repairs, disease recurrences, and other applications. ASA/SIAM. Providence, (Vol. 10)., Rhode Island.

Peña, E.A. (2006). Dynamic modeling and statistical analysis of event times. Statistical Science, 21(4), 487500.

Peña, E.A., \& Hollander, M. (2004). Models for recurrent events in reliability and survival analysis. In Mathematical Reliability: An Expository Perspective (pp. 105-123). Springer, Boston.

Pham, H., \& Wang, H. (1996). Imperfect maintenance. European Journal of Operational Research, 94(3), 425-438.

Rausand, M., \& Hoyland, A. (2004). System reliability theory: models, statistical methods, and applications. Wiley, New York.

Rigdon, S.E., \& Basu A.P. (2000). Statistical methods for the reliability of repairable systems. Wiley, New York.

Simpson, K.G.L., \& Kelly, M. (2002, June). Reliability assessments of repairable systems-is Markov modelling correct?. In Safety and Reliability. Taylor \& Francis, London, pp. 19-39.

Tan, F.R., Jiang, Z.B., \& Bai, T.S. (2008). Reliability analysis of repairable systems using stochastic point processes. Journal of Shanghai Jiaotong University (Science), 13(3), 366.

Tong, L., \& Liang, Y. (2005). Forecasting field failure data for repairable systems using neural networks and SARIMA model. International Journal of Quality \& Reliability Management, 22(4), 410-420. 
International Journal of Mathematical, Engineering and Management Sciences

Vol. 6, No. 1, 180-192, 2021

https://doi.org/10.33889/IJMEMS.2021.6.1.011

Wu, W., Ma, J., \& Liu, L. (2011, June). Research on FFOP prediction approach of a pulse generator based on homogeneous Poisson process. In The Proceedings of 20119 th International Conference on Reliability, Maintainability and Safety (pp. 334-338). IEEE. Guiyang, China.

Xiao, G., \& Li, Z. (2008). Estimation of dependability measures and parameter sensitivities of a consecutive$k$-out-of- $n$ : f repairable system with $(k-1)$-step Markov dependence by simulation. IEEE Transactions on Reliability, 57(1), 71-83.

Yang, Q., Zhang, N., \& Hong, Y. (2013). Reliability analysis of repairable systems with dependent component failures under partially perfect repair. IEEE Transactions on Reliability, 62(2), 490-498.

Zheng, Z., Cui, L., \& Hawkes, A.G. (2006). A study on a single-unit Markov repairable system with repair time omission. IEEE Transactions on Reliability, 55(2), 182-188. 